\title{
Orden social, Estado y escuela: de la producción de lo común a la producción de la diferencia
}

\author{
Social order, state and school: from the production of the \\ common to the production of the difference
}

HÉCTOR MONARCA (Universidad Autónoma de Madrid), NOELIA FERNÁNDEZ GONZÁLEZ (Universidad Autónoma de Madrid) y ÁNGEL MÉNDEZ-NÚÑEZ (Universidad Autónoma de Madrid)

Artículo recibido: 4 de mayo de 2020

Solicitud de revisión: 10 de julio de 2020

Artículo aceptado: 3 de agosto de 2020

Monarca, Héctor, Fernández González, Noelia y Méndez-Núnez, Ángel (2020). Orden social, Estado y escuela: de la producción de lo común a la producción de la diferencia. Recerca. Revista de Pensament i Análisi, 25(2), pp. 117-136.

Resumen

En este texto abordamos el papel de la escuela en la producción de lo común y la diferencia como mandatos del Estado en el marco de los procesos de producción-reproducción del orden social. Inicialmente, discutimos lo común como relato de ficción demandado a la escuela durante los procesos de formación del Estado-nación. A continuación, abordamos lo común producido por la escuela, como efecto desbordado del relato de ficción de lo comúnuniversal. Finalmente, analizamos el mandato de la escuela contemporánea para la producción de la diversidad-diferencia, como nuevo régimen de verdad en la producción del individuo solipsista y las comunidades cerradas hiperfragmentadas. Como cierre, planteamos la paradoja de este nuevo mandato escolar para la producción de la diversidad-diferencia en un momento histórico en el que se ha consolidado un cierto común que podría servir de plataforma para disputar ese orden capitalista que hoy, como reverso, es lo único común globalizado.

Palabras clave: orden social, Estado, escuela, común, diferencia.

Abstract

This text addresses the role of the school in producing the common and the difference, as «mandates» of the state, within the processes of production-reproduction of the social order. We begin by discussing the «common as a fiction narrative» which is required to be produced by the school in the processes of nation-state building. Then, we address the «common produced» by the school as an overflowing effect of this fiction narrative about 
the common-universal. Finally, we analyse the current mandate of the school to produce the «diversity-difference» as a new regime of truth that generates solipsistic individuals and closed hyper-fragmented communities. We conclude by posing the paradox of this new school mandate to produce diversity-difference, that emerges just in a historical moment where a certain kind of consolidated common could have worked as a platform for dispute the capitalist order that nowadays, as a reverse, is the unique globalized common.

Key Words: social order, State, school, the common, difference.

\section{INTRODUCCIÓN: ESTADO, ESCUELA Y LO COMÚN COMO FICCIÓN}

La escuela no puede entenderse al margen del proceso de institucionalización de la modernidad por el cual se configuró el sistema-mundo (Wallerstein, 1983): el orden social contemporáneo. En este sentido, como institución del orden, desde la emergencia del Estado-nación, la escuela de masas ocupa un lugar entre la producción y la reproducción del mundo social. Así, desde el origen del Estado-nación, a la escuela se la ha embarcado en la producción del nuevo sistema social y político que sustituía al Antiguo Régimen y del sujeto que este precisaba (Pineau, Dussel y Caruso, 2001). La escuela de masas asumía el mandato de colaborar en la arquitectura de la polis, inaugurando así un nuevo e inevitable vínculo entre lo político, la política y la educación (Castoriadis, 1997). Esta arquitectura se centró y sostuvo de manera muy especial en la construcción e instalación de un relato de lo común que incluía la fabricación cohesionada de: una nación común, una historia común, una cultura común, un territorio común, una religión común $\mathrm{y}$, bajo todo lo anterior, un nosotros que configuraba la identidad del sujeto común. Un nuevo orden estructuralgnoseológico que quedaría plasmado en instituciones, organización social, formas de vida y un nuevo individuo al que se lo consideraba libre e igual en derechos y obligaciones. Un sujeto que, en tanto ciudadano, emergía como producción de lo común en este nuevo relato y nueva materialidad sociohistórica que era el Estado-nación.

Este nuevo relato del Estado-nación se configura sobre ciertos aspectos previos aparentemente comunes a partir de los cuales otros son producidos en nuevos e intensos procesos normalizadores-homogeneizadores que son la base de ese nosotros contingente y de esa ciudadanía fabricada como representación de la individualidad moderna, base de la libertad y la igualdad abstractaficticia. Individuos que serían, al menos en esa comunidad imaginada (Anderson, 2006), los depositarios de unos derechos y deberes considerados universa- 
les (Wallerstein, 1983; Žižek, 2007). Este relato es producido y promovido por el Estado-nación, quien pasa a ser la expresión y el representante del interés o bien común, el cual es presentado separado, ajeno e independiente del mismo Estado, no vinculado a «los reales intereses particulares y colectivos» a modo de «una comunidad ilusoria» (Marx y Engels, 1968: 35). Así, los procesos de producción y acumulación de la riqueza, que el Estado sigue favoreciendo, sosteniendo y promoviendo, como así también sus efectos en la organización social y las formas de vida, quedan enmascarados y distorsionados por el relato de lo común: bajo la ficción del interés y del bien de todos y todas.

Por tanto, mientras se producía este común como relato-representación, se construía un espacio, la polis, como el territorio común —como comunidad política-que debía funcionar de acuerdo con este supuesto, bajo una ficción de igualdad y libertad naturales. La realidad estructural del orden social se presenta separada del Estado y de un orden y, sobre todo, invisibilizada en el relato-representación ficcional de lo común, la igualdad y la libertad. De esta manera, podemos pensar junto con Grüner (2016) que este relato de lo común elimina la diferencia y el conflicto en su interior contingente del nosotros, a la vez que expulsa al Otro a un exterior igual de contingente.

Así, lo común es en este contexto, en primer término, un relato que invisibiliza las prácticas sociales, políticas y económicas que ponen en evidencia una realidad más allá del relato, de la representación construida acerca de ese nosotros-común. Una representación que se sostiene en la racionalidad moderna como mito universal, en cuya ficción se esconde una realidad violenta, sangrienta y desgarrada sobre la que se viene edificando el sistema-mundo contemporáneo durante los últimos quinientos años (Luxemburgo, 1975; Grüner, 1998; Lander, 200o; Quijano, 2000; García Olivo, 2009; Federici, 2014), su realidad material-simbólica.

En este sentido, ese relato de lo común del Estado-nación es una expresión de la modernidad en la que esta, tal como expresó Castro-Gómez (2000: 88), fue una «máquina generadora de alteridades» que, a la vez que definía lo que sería entendido como propio del nosotros, los sujetos del Estado-nación, excluía «de su imaginario la hibridez, la multiplicidad, la ambigüedad y la contingencia de las formas de vida concretas». Los rasgos de lo común a producir que caracterizarían a los sujetos del Estado son una forma de ver, representar y de ser necesarias para el mismo. Por tanto, resaltamos aquí, junto con Castro-Gómez (2000), que la edificación de lo común como relato, como ficción, como imaginario y como realidad del Estado-nación es indisociable a la «invención del otro» «no-ser, la nada, la barbarie» (Dussel, 2011: 22). En este 
sentido, tanto el nosotros como el Otro debían ser producidos materialsimbólicamente en un contexto en el que «el imaginario de la "civilización" exigía necesariamente la producción de su contraparte: el imaginario de la "barbarie"» (Castro-Gómez, 2000: 91).

Por eso, la producción de lo común, del nosotros, de la civilización moderna, se asocia a la producción de categorías clasificatorias, diferenciadoras y jerarquizadoras del mundo (Bourdieu, 2000, 2014; Gandarilla, 2016), que contribuyen a dar sentido al orden social y a legitimarlo; un orden materialgnoseológico con efectos diversos para el mismo mundo social. Algunos de los análisis-críticas marxistas, anarquistas, feministas y decoloniales han arrojado luz sobre estos efectos (Castro-Gómez, 20oo; García Olivo, 2005; Cappelletti, 2010; Caffentzis y Federici, 2015; Grüner, 2016; Fraser y Jaeggi, 2019; Mies, 2019). Estos análisis ponen de manifiesto la manera claramente diferenciada en la que ese común beneficia a los sujetos y a los grupos. El bien común y el bien de los sujetos, que bajo esa excusa son producidos, reflejan contradicciones que precisan de prácticas legitimadoras y disciplinadoras (Cullen, 20o8) capaces de mantener ese orden. En palabras del autor recién mencionado se da así una «tensión entre el deber y el deseo, por un lado, y, por el otro, entre formas históricas concretas de organización social y el nebuloso ideal del "progreso de la humanidad"»(Cullen, 2008: 90).

La producción del sujeto del Estado-nación supone socializarlo en esta racionalidad que servirá de plataforma para pensar el mundo, habitar la polis. En este proceso que explica nuestro sistema-mundo capitalista, patriarcal y colonial, lo que tenía que ser común era este régimen de verdad (Monarca, Fernández-González y Méndez-Núñez, en prensa), de saber-poder de la modernidad, el cual configuró un «tiempo homogéneo y vacío que fagocitó las historicidades paralelas y autónomas de las sociedades colonizadas y explotadas desde el propio surgimiento del capitalismo» (Grüner, 2016: 52).

Mientras el Estado-nación - y sus instituciones- era producido, lo era su ser-sujeto nacional. La escuela debe asumir así este mandato de lo común del Estado-nación que se traduce en un tipo de racionalidad pedagógica que «neutraliza las diferencias sociales en las que se producen el lenguaje, el pensamiento y la acción» (Popkewitz, 1994: 205) a través de un lenguaje universal e instrumental que «homogeneiza las distinciones y conflictos sociales» (Popkewitz, 1994: 212), poniendo un manto de oscuridad a la relación entre Estadosociedad-escuela, lo político y la política, y en general a su base estructuralmaterial-simbólica. En el marco del Estado-nación, la escuela debe fabricar un tipo de ciudadano civilizado, lo que era imprescindible para la continuidad, el 
desarrollo y el progreso del orden social capitalista. Para ello, este relato común ficticio esencializa la identidad nacional eurocéntrica mediante construcciones mitificadas del relato nacional del Estado y de Europa, con las que logra ocultar no solo el carácter artificial de este relato, sino también el que es en realidad el mandato de la escuela: la producción de esas identidades nacionales supuestamente naturales y universales, proyectando así este pasado fabricado hacia el futuro. Por tanto, la escuela se ubica aquí como institución indispensable para el emergente Estado-nación en sus formas de producirse y reproducirse. La sociedad que emergía de esta nueva forma liberal-capitalista precisaba de mecanismos de socialización que asumieran los procesos necesarios para la incorporación-adhesión al orden social emergente. La escuela de masas se instala así como dispositivo de gubernamentalidad (Pineau, 2001; García Olivo, 2005, 2009; Castro-Gómez, 2010) para producir un determinado tipo de sujeto: la identidad nacional funcional al orden social que el Estado precisaba.

En el Antiguo Régimen la socialización de la mayoría de la gente se producía principalmente en su misma vida cotidiana, participando de forma más o menos directa en las formas de vida de su entorno, principalmente con prácticas socializadoras no institucionalizadas (Lundgren, 1992). Con la emergencia del Estado-nación - y el nuevo orden social asociado- se precisa de una institución en la que recaiga la socialización, siendo la escuela la que asume esta tarea, como responsable de producir al ciudadano, al sujeto del Estado, de la polis, del orden.

\section{ESTADO, ESCUELA Y LO COMÚN PRODUCIDO}

El Estado-nación, capitalista y liberal, como «todo régimen político produce siempre un determinado tipo de identidades a través de las cuales se conforma la cohesión social y se da sentido a ese espacio común» (Yannuzzi, 2009: 2), proceso que, como sostiene esta autora, está cargado de conflictos, imposiciones, resistencias y disputas, en tanto

[...] la resolución específica que se adopte en cada caso particular supone necesariamente establecer relaciones concretas de poder que se definen a partir de una frontera imaginaria que instituye, en virtud de las relaciones de fuerza existentes en la sociedad, los alcances del espacio de lo común, por oposición a la institución de un Otro que queda por ello mismo excluido (Yannuzzi, 2009: 3). 
En este sentido, que la escuela haya surgido como una institución socializadora, colaboradora en la producción y la reproducción del orden social, no puede leerse como algo excepcional. Todas las sociedades y grupos humanos han generado prácticas socializadoras de diverso tipo con la intención de incorporar a las personas a su orden social o, dicho de otra manera, incorporar el orden social a los sujetos. Todas las prácticas socializadoras son prácticas orientadas a incorporar el orden social en los sujetos y viceversa.

En cualquier caso, que la producción del relato de lo común haya asumido los rasgos antes mencionados no significa que no haya tenido efectos vinculados a sus pretensiones de ficción en el orden estructural-gnoseológico. Esto no quita que, siempre bajo las características antes analizadas, se haya construido algún tipo de común real, una cultura compartida, reconocida como tal por sujetos que llegan a autopercibirse como libres e iguales como efecto de esta acción de Estado y de los procesos de socialización en general que se dan en el marco del nuevo orden social. Igualdad y libertad que, en este caso, no es aquel rasgo esencial-natural que estos relatos de lo común y la universalidad expresan, sino un producto del mismo. El relato común de libertad e igualdad como ficción, y también como utopía, tuvo efectos en las formas de vida del Estadonación, en los deseos y las aspiraciones, en reclamos, luchas y disputas (Borón, 2002). El relato de lo común tuvo efectos en la configuración de un espacio público compartido, sobre el que el mismo Estado asumió responsabilidades para su existencia, sostenimiento y garantía. Es clave entender aquí el espacio público como el encuentro del relato de lo común con las prácticas concretas de sujetos, grupos sociales, clases que disputan la ficción y la desbordan, disputando así el orden establecido y construyendo un nuevo común producido.

El relato de lo común como trasfondo socializador de la escuela -que a la vez tiene su propio trasfondo: régimen de verdad invisibilizado- tiene efectos en la polis real y deseada. El peso del relato tiene que ver con las relaciones desiguales del poder que lo sostienen y producen y por los sujetos producidos que lo reproducen. En y por la escuela, lo común ya no es solo un relato: es también una experiencia compartida - que no significa que igual para todosde espacio-tiempo que crea contemporaneidad, que crea lazos de dependencia e intereses comunes en una sociedad de clases. Un interés común que no es solo una idea, sino que «se presenta en la realidad, ante todo, como una relación de mutua dependencia de los individuos entre quienes aparece dividido el trabajo» (Marx y Engels, 1968: 34 ).

La insistencia, la imposición y la inculcación a lo largo del tiempo llevan finalmente a distintos grados de adhesión e, incluso, también a distintos tipos 
de disputas. Del común como relato se va pasando a un cierto común real producido. Los efectos de ese relato de lo común pueden ser vistos en formas de vida compartidas, aceptadas, buscadas, deseadas; formas de convivencia ya normalizadas, normas compartidas-asumidas, un marco cultural en el que se dan procesos de identificación y diferenciación, un lenguaje, creencias, un sentimiento-identidad con algún tipo de anclaje en ese común; adhesiónaceptación-admiración a símbolos, relatos, prácticas, moral, a un ethos social que da cohesión a un grupo: una cohesión arbitraria producida-impuesta, reproducida y también, después, deseada, buscada, esperada. En este común producido la escuela ha jugado un papel clave construyendo, además de un relato de ficción, una utopía de igualdad subjetivada, con un sentido en parte sujetado y en parte disputable, que se materializa en disputas, luchas y reclamos, como así también en la escuela que queda en parte desbordada de sus rasgos iniciales.

Dentro del orden social conformado, la escuela pasó a ser también una institución deseada, reclamada, exigida. La ampliación y la extensión de la enseñanza común y obligatoria surge, en primer lugar, por las luchas y los discursos progresistas, como una forma de disputar el relato de ese común excluyente que inicialmente fue la escuela de masas. Esta escuela pública, común y obligatoria pasó a ser un reclamo del proletariado y de los sectores sociales excluidos de ese orden; pasó a ser uno de los campos donde se daba la lucha de clases. Pasó a ser también el reclamo de ese Otro excluido en el nosotros civilizado.

De esta manera, se fue vinculando esa educación común con el brindar conocimientos a las nuevas generaciones para poder participar en el mundoorden social (Durkheim, 1996) y, para otros, para cambiarlo o subvertirlo (Freire, 1985). La lucha que diferencialmente se fue dando en diversos países y con distintos efectos por la ampliación de la obligatoriedad fue una constante hasta conseguir que cada vez más sectores de la población no solo finalicen la enseñanza secundaria, sino que accedan a la universidad (Monarca, 2011). Para muchos sectores de la población de distintos países, este fue - y sigue siendoun deseo.

Pasadas las primeras fases de una escuela de masas principal o meramente disciplinadora, inculcadora del relato común del Estado-nación como comunidad imaginaria, entramos en la fase de una escuela para la enseñanza común conformada por aquellos elementos considerados cultural, científica y socialmente relevantes para la sociedad en cuestión (Gimeno Sacristán, 200o), ya en el marco de un orden que no logra sujetar del todo a las voces discordantes. 
En este sentido, pasada lo que podríamos llamar una primera fase de una escuela claramente orientada a transmitir-inculcar aquellos elementos imprescindibles para el nuevo orden emergente con el Estado-nación, se entra en una fase en la que el sistema educativo se edifica bajo el supuesto de una escuela común que será la base para seguir avanzando en la pirámide educativa. El relato común de la igualdad abstracta de esa comunidad imaginaria (Anderson, 2006) que la misma escuela divulgó e inculcó, no solo contribuyó a mantener la ficción, sino también, en algunos casos, a hacerla menos ficción y más real - aunque siempre de manera diferenciada - e incluso a desafiarla como ficción, como relato, gracias a procesos de crítica, lucha, reclamo, cuestionamiento del orden social y la escuela (Freire, 1985; Tomassi, 1988; García Olivo, 2005; Trasatti, 2005).

En este sentido, más allá de la crítica ya explicitada al relato de ficción de lo común, la escuela ha contribuido con algunos procesos considerados relevantes en la sociedad-cultura contemporánea; por ejemplo, ha jugado un papel importante durante mucho tiempo en la alfabetización de la población (práctica en muchos momentos y lugares prohibida para la mayoría o para ciertos sujetos), en el acceso a ciertos saberes, en la adquisición de herramientas para la vida social... En este sentido, aunque la sociedad era desigual antes de la escuela y lo sigue siendo ahora, con la escuela, este relato y esta experiencia de lo común fue calando de diversas maneras. Incluso, en determinados contextos y momentos históricos, la escuela sí cumplió para algunos sectores de la población con esta profecía de la igualdad. Cuando menos, contribuyendo a que ciertas condiciones de la vida contemporánea mejorasen, principalmente con ciertas opciones relacionadas con la división social del trabajo.

La escuela, esta institución pensada para inculcar un relato de lo común y producir al sujeto sujetado del Estado-nación, tiene también efectos estructurales-simbólicos, posiblemente imprevistos en su inicio, al menos en cuanto que la ficción no es capaz de sujetarlo totalmente, escapándose de ella, liberándose hacia un común real dispar, diverso, pero común real. La escuela ha llegado a ser un «sublime objeto de deseo» (Žižek, 2016), que completa un vacío, la falta en sentido lacaniano: se espera de ella que ofrezca algo necesario para habitar de una manera mejor la polis que sin ella. Por eso, la escuela ha sido exigida y reclamada y se ha disputado su espacio, su proyecto y contenido, sus mandatos; no se abrió como espacio común real sin más, sino como producto de la lucha continua e incesante, la disputa de «lo político» (Castoriadis, 1997). 
Con un funcionamiento dispar, tanto por países como en el interior de los mismos, la escuela ha permitido construir, después de décadas, una cultura con elementos comunes, con experiencias comunes, y ha contribuido a desarrollar sentidos compartidos que más o menos nos identifican o, al menos, identifican a una parte considerable de la población. En algunos casos fue y es una de las instituciones que nos ha permitido tener una experiencia común, ya no por buena o por mala, sino por frecuente y sistemática, la experiencia escolar es tal vez una de las más comunes de nuestra contemporaneidad, aunque esta refleje también vivencias diferentes. En muchos países, ha colaborado en procesos de movilidad social y, por otro lado, contribuyó a través de praxis alfabetizadoras al acceso y desarrollo de la teoría-pensamiento crítico. Cada vez más personas en los distintos Estados y en el mundo han pasado por ella, es cada vez más demandada, sobre todo por sectores sociales que no se beneficiaron de ella. Parece que, sin ella, al menos en su mejor versión, el acceso a ciertos elementos de la cultura, imprescindibles para una vida en condiciones de igualdad, podrían estar en riesgo, por lo menos para una parte de la población.

En este sentido, después de la crítica necesaria hecha en el apartado anterior, es preciso resaltar ahora que, en cualquier caso, ese recorte cultural arbitrario que formó parte del relato de lo común asumido por la escuela terminó teniendo efectos como cultura común real. En esta línea, Diker (2008: 148) nos recuerda que «el recorte cultural que la escuela (común, básica, elemental) transmite es significado como común y produce efectos sobre la construcción de una cultura común solo en tanto y en cuanto se dirige a todos». La autora destaca un hecho que puede ser de importancia para este análisis: «lo común no preexiste a la escuela, sino que debe ser construido por ella» (Diker, 2008: 159). Destacamos así que, más allá de la arbitrariedad del recorte cultural que la escuela transforma en un currículum explícito y oculto que valida como universal, presenta la novedad de que, por primera vez en la historia, se piensa en que algo así debe dirigirse a todos y todas (Diker, 2008).

La escuela es una institución de poder - perteneciente al orden, lo político- y justamente por ello es foco de la política, de la disputa, muy especialmente por su contenido, su función. La escuela, con el tiempo, ha pasado a ser un objeto de deseo y, en este contexto, parece sugerente verla como espacio de y para la disputa, en tanto que terminó ubicada, a lo largo del tiempo, en un lugar entre lo político —el orden instituido_y la política — la disputa de este orden- (Castoriadis, 1997). Por eso, se la puede entender como institución tensionada, permanentemente institucionalizándose, en un proceso que no 
finaliza de una vez y para siempre; como parte del orden, de lo político, se ha transformado desde hace décadas en objeto de la política, en un objeto de disputa y en un espacio a través del cual se disputa el orden.

\section{ESTADO, ESCUELA Y LA PRODUCCIÓN DE LA DIVERSIDAD- DIFERENCIA}

Hoy en día, bajo la nueva cara neoliberal del capitalismo, el orden social parece estar necesitando una reorientación en las funciones de sus instituciones, en este caso, reformular el mandato de la escuela común. Lo importante ya no es que produzca, transmita y reproduzca la cultura común, sino todo lo contrario: que asuma ahora la producción de lo diverso, lo diferente y la diferencia. Ahora no se buscaría construir o reforzar ningún nosotros, la producción del individuo único e irrepetible parece ser ahora su mandato, la máxima expresión del sujeto solipsista del liberalismo. Ya no se trata de desarrollar un común de ficción ni un común real, ni una cultura común, ni una identidad común, ni un bien común... sino de contribuir a desarrollar, alabar y resaltar todo aquello que apele a supuestos rasgos singulares en los sujetos, como si se tratase del rescate de una esencialidad natural olvidada, perdida por los avatares de la historia. El reverso del relato de lo común es el relato de lo diverso, de la diferencia, dos caras de una ficción que sirve al mismo orden de las cosas, al igual que el reverso del relato abstracto de la igualdad es el de la desigualdad real. Tanto lo común como lo diverso son producto del orden social, del orden de las cosas, son productos sociohistóricos asociados a las relaciones de fuerza y de poder (Žižek, 2007); nada que podamos naturalizar.

El estallido de lo social, la disolución de aspectos claves de la modernidad en la que nos encontramos, de su relato de lo común y universalidad y de sus instituciones, no significa en absoluto la desarticulación del sistema-mundo capitalista contemporáneo, aunque desde ciertos abordajes pareciera generarse la ilusión de un nuevo y mejor orden emergente a partir de un idílico proceso articulatorio (Borón y Cuéllar, 1983; Monarca, Fernández-González y MéndezNúñez, en prensa). Justo en este momento histórico en el que la escuela pudo haber producido un cierto común real, estructural-simbólico, al menos en ciertos lugares y para algunas personas, que haya logrado ser un lugar común para muchos niños, niñas y adolescentes, que se haya transformado en objeto de deseo por parte de los sujetos, la producción de la diversidad y la diferencia por parte de la escuela y del orden social capitalista, cuando menos, invita a la 
sospecha. Es decir, justo cuando parece haberse cumplido, al menos en parte, sus mandatos originarios, tal vez más allá de lo que el relato inicial haría suponer, es cuando el mandato cambia. Es entonces cuando esta aparente casualidad o la aparente normalidad y naturalidad que está adquiriendo este nuevo relato de la diferencia y la diversidad precisa de una mirada crítica que nos conduzca con cautela.

Habiendo sido críticos con el relato de ficción sobre lo común y universal sobre el que se edificó la polis moderna, el Estado-nación y su orden social asociado, y habiendo aportado también elementos para pensar eso mismo desde otra perspectiva, no podemos ahora asumir, sin más, un nuevo relato del orden, ahora el de la diversidad y la diferencia. Estas también existieron, existían, existen y existirán a pesar -y más allá- de lo discursivo, de los relatos de lo común; al igual que ahora sucede con lo común, este existe, a pesar $-\mathrm{y}$ más allá- de estos discursos de la diversidad y la diferencia. En este sentido, este nuevo relato sigue operando como aquel otro relato que ahora se desvanece por medio de las acciones de poder-saber que en esta dirección se ejercen. Nada diferente como proceso del orden que marca la forma de producir y reproducir lo social; se vuelve a ejercer violencia, ahora sobre lo común construido, lo social como referente compartido, lo público como espacio material-simbólico de todos y todas. Violencia sobre los relatos de lo común y sobre los sentidos, los territorios, las aspiraciones, los deseos y los bienes comunes. Se deconstruye la polis común, la sociedad, de la misma manera que antes fue construida: arrasando lo que hay, lo que existe, invisibilizando y silenciado el proceso que está teniendo lugar.

Por eso es preciso pensar en la escuela y en su mandato bajo este nuevo relato y pensar en sus efectos materiales y simbólicos. Como nos explicaba Diker (2008), antes se asumía que lo común no preexistía a la escuela, que construirlo era su función, su tarea, su mandato. Cierto es que ha funcionado de manera muy diferenciada y que el proceso debe ser abordado críticamente, aspecto sobre el que ya se ha insistido. Pero igual de cierto es que durante décadas edificó un lugar desde el que comprender el mundo, aproximarnos a él, desenvolvernos en él, incluso, en algunos casos, para cuestionarlo y disputarlo.

La escuela descolocada, habiendo normalizado cada vez más el relato de la diversidad y la diferencia - al igual que antes asumió el relato de lo común-, parte de la premisa de producir la diversidad-diferencia, aunque bajo una peculiar idea que da tranquilidad de conciencia y supuesta legitimidad: la diversidad-diferencia son rasgos esenciales-naturales de niños, niñas y adolescentes a quienes, como misioneros del orden, hay que salvar y atender, ofreciendo la 
acción idónea para responder $\mathrm{y}$ atinar con ese ser único e irrepetible: el alumno solipsista de siglo XXI, producto del discurso liberal-capitalista. El proceso de producción de este sujeto, ahora más del sistema-mundo capitalista-patriarcal-colonial que del Estado, al igual que antes, queda totalmente invisibilizado. Sin embargo, a diferencia de entonces, ahora la escuela da por hecho que existe un común -incluso más abstracto y de ficción que el anterior-, el cual actúa produciendo diversidad-diferencia, en tanto que cualquier mínimo detalle que no encaje debe ser no solo considerado, sino atendido. Curiosamente, dentro de ese común ficticio se incluyen cosas que fueron históricamente metas de la escuela, como parte de ese mandato de lo común que la escuela tenía que producir y que ahora son tratados como rasgos esencialesnaturales personales que hacen referencia a una gran variedad de cuestiones: comportamientos-habilidades-conocimientos-actitudes-valores que pareciera que niños, niñas y adolescentes deben poseer como rasgos independientes de la acción escolar, como rasgos genética y naturalmente heredados o aportados por un normalizado contexto familiar (Kaplan y Ferrero, 2003). Si esto no está, hay diversidad y diferencia, la cual exige una respuesta peculiar, a partir de la cual, con bastante seguridad, no se terminará produciendo ningún común real posible, ni siquiera de ficción, ya que todos y todas somos esencial y naturalmente diferentes.

De esta manera, con el pasar del tiempo, la idea de que la escuela tenía que transmitir la cultura común y producir lo común desaparece. Sin embargo, paradójicamente, el relato de la diversidad y la diferencia se sostiene en el supuesto de que, para entrar y funcionar en ella, es preciso poseer un bagaje supuestamente común que da por hecho que sí existe, algo así como un bagaje escolar ya construido previo a la misma escolarización. En este sentido, alineada con las tendencias del orden, ahora la escuela debe producir empresarios de sí: trabajo autónomo, autoaprendizaje, autodisciplina. Las niñas, los niños y los adolescentes pasan a ser los responsables de su propio aprendizaje, empresarios de sí mismos, pero solo de sí, no partícipes en la construcción de lo social, del orden estructural-gnoseológico: eso ya está dado, no se discute, no es construible por el sujeto.

De esta manera, la escuela deposita «sobre cada una de nuestras espaldas la tarea y la responsabilidad de construir nuestro éxito o, lo que es más probable, de soportar y explicar nuestro fracaso» (Dussel, 2007: 22). Se trata, tal como afirma esta autora, de un individualismo del autodiseño que «se configura así como un nuevo patrón que vuelve mucho más difícil establecer lazos colectivos, formas de autoridad tradicionales, y pautas de transmisión culturales 
más estables y duraderas» (Dussel, 2007: 22). En este contexto, la producción de la diversidad y la diferencia puede llegar — ha llegado y está llegando- a tal extremo que produce la tendencia al aislamiento, «a encerrarse en el barrio, en la familia, incluso en el cuarto propio, y conversar solo con aquellos a quienes uno "entiende" o comparte gustos» (Dussel, 2007: 22). De manera parecida podemos analizar ciertos fenómenos identitarios y culturales que producen lo que podemos llamar sujetos y comunidades auto-cercadas, encerradas; como si fuesen la encarnación de rasgos esencial y genéticamente heredados. ${ }^{1}$ En un contexto así lo público y lo común se diluye, se repliega, y paradójicamente lo privado pasa a formar parte de un sentido común naturalizado.

\section{ESTADO, ESCUELA Y LA PRODUCCIÓN DE LA DIVERSIDAD- DIFERENCIA EN UN CONTEXTO TOTALIZADO INVISIBILIZADO}

Así, el individuo solipsista y la comunidad hiperfragmentada producida por el nuevo relato de diversidad-diferencia aparecen en una sociedad estalla$\mathrm{da}$, aislados en un universo inconexo bajo un orden incapaz de ser visibilizado. El capitalismo-patriarcado-colonialismo, como orden globalizado, emerge como único marco común real fuera de todo relato, orden que sigue valiéndose del Estado-nación, entre el descaro y el desprecio, para jugar a sus anchas según las circunstancias, jahora más social, ahora más competitivo!, a modo de comodín que garantiza sus necesidades de producción y acumulación de la riqueza.

La producción de la diversidad, la diferencia y el estallido de lo social van de la mano para generar nuevamente la ilusión de nuevo orden, reino del individuo solipsado, que echa tierra una vez más sobre los caminos existentes que permiten conectarnos con los tiempos ya pasados, desactivando la memoria de los hechos acontecidos: la mentira y la barbarie del capitalismo, el patriarcado y el colonialismo. En este nuevo orden solo queda el solus ipse y, en todo caso, comunidades puras, cerradas y fragmentadas, alejadas de cualquier sospecha de contaminación del Otro, a modo de comunidades sin historia, sin procesos de producción y reproducción, sin relaciones de poder que las definan como orden, comunidades puestas desde el origen de los tiempos por alguna divini-

En este trabajo estamos realizando una crítica a la producción de la diversidad y la diferencia como prácticas del orden social capitalista no a las luchas y procesos reivindicativos que, justamente, surgen como resistencia y disputa de este orden social. 
dad o la misma naturaleza. Comunidades que ahora aparecen como eternas, naturales y esenciales, como luces que deslumbran sobre un fondo que las contiene, las sujeta y las atrapa, sin poder ser visibilizado.

De esta manera, el sistema-mundo, el orden social globalizado, no tiene rival ante un común fragmentado en individuos y comunidades desconectadas. Mientras lo social y lo común estallan, la diversidad y la diferencia se usan para ocultar la desigualdad de un mundo social totalizado por el capitalismo y el mercado (Grüner, 1998; Žižek, 1998).

Se genera así la paradoja de un individuo aparentemente reforzado, pero que habita en una polis en ruinas, una sociedad estallada, en la que ya no hay dónde morar con otros y otras. Estos procesos individualizantes productores de la diversidad y la diferencia dicen no buscar certezas ni verdades, como si estas existiesen por sí solas, fuera de las relaciones de poder en las que se configuran, pero olvidándose también que el estallido, la deconstrucción, la fragmentación y el hibridismo también son una verdad emergente de las relaciones de poder. No es que haya desaparecido la producción de la certeza o la verdad común: mientras esta sigue produciéndose como siempre ha sido, queda recubierta por la ilusión solipsista de que el individuo mismo o la comunidad cerrada bastan para producirla.

A excepción del sistema-mundo capitalista totalizado, ya no hay certeza común. Las certezas comunes han caducado por decreto del anterior, solo se han autorizado verdades individuales o locales, cuantas más diversas, dispersas, fragmentadas y desconectadas mejor; salvo pseudopluralidad supuestamente articulada: ese hibridismo que se presenta a modo de estandarte de libertad de un irreal e imposible sujeto no sujetado. Tal como nos recordaba Yannuzzi (2009: 9) «el mundo parece así feudalizarse, negando con ello la política, es decir, la conformación de un espacio común». En esta línea, tal como sostiene Žižek (1998: 168), hoy nos enfrentamos «con un proceso inverso al de la temprana constitución moderna de la Nación».

\section{REFLEXIONES FINALES: ESTADO, ESCUELA Y LA PRODUCCIÓN DE UN COMÚN NECESARIO}

Pero si la polis desaparece como el lugar común y la posibilidad de lo público, si la sociedad se desvanece y no hay más que individuos y una cantidad de grupos heterogéneos que se presentan a sí mismos como únicos portadores legítimos de su mismidad-identidad, lo común solo sería posible en el interior 
de lo particular: acotado y molecular, fragmentado, dividido y debilitado, cada vez más incapaz de la interrelación, la cooperación y la solidaridad. En la falacia de una igualdad erigida bajo el relato de la diversidad y la diferencia como rasgos esenciales a respetar y atender, se esconde la única diferencia significativa realmente problemática: la producción y la acumulación de la riqueza, la desigual distribución del poder, la división social del trabajo y la sociedad de clases.

Por tanto, esta nueva tendencia del orden y nuevo mandato de la escuela no solo no resuelve el problema del relato de lo común como ficción, sino que ha producido incluso el estallido de ese común real, producto sociohistórico de la lucha, la crítica, la disputa por el orden: sus procesos de producción y acumulación de la riqueza, sus procesos de diferenciación y jerarquización, la sociedad de clases. No hay diversidad ni diferencia esencial que justifique esta sociedad molecular naturalizada de los grupos o individuos solipsistas. En el interior de estos grupos también se dan procesos de regulación, control y jerarquización a partir de los cuales se erige, a modo de poder-verdad, una identidad, la que será defendida por los portadores supuestamente legítimos. Por tanto, solo supone un nuevo orden de las cosas, producto de las relaciones de poder-saber.

En este sentido, plantear este nuevo orden basado en la diversidad y la diferencia naturalizadas que estallan lo social, justamente ahora, momento en el capitalismo se ha hecho más universal que nunca, más común que nunca, dirigiendo el mandato de la escuela a producir la diferencia, a un individuo hiperdesconectado de cualquier cuerpo-totalidad posible que genere cierto sentido común más allá de las posiciones particulares-individuales, locales e inmediatas (sentidos comunes que permitan y faciliten la acción colectiva), nos deja en un punto igual de tremendo que ese común-universal que arrasó y fagocitó las otras contemporaneidades e historias paralelas.

Es realmente paradójico, el mismo cinismo de siempre, esta alabanza a la diversidad y la diferencia y hacer de su producción el mandato de la escuela contemporánea, cuando no es preciso un análisis demasiado profundo ni crítico para poder ver una realidad que «da testimonio de la homogeneización sin precedentes del mundo contemporáneo» (Žižek, 1998: 176), objetivado en el sistema-mundo capitalista, colonial y patriarcal. Este nuevo relato de la diversidad y la diferencia se presenta a modo de restauración de los supuestos efectos del relato de lo común como orden avasallador; pero olvida, tal como evidenciaba Žižek (1998: 182), que «la politización del conjunto de luchas par- 
ticulares, que deja intacto el proceso global del capital, claramente resulta insuficiente».

Cínicamente, este relato de la diversidad y la diferencia, funcional al sistema-mundo capitalista-liberal, produce un nuevo orden gnoseológico que nutre los cuestionamientos «a toda forma pensable de "identidad" estabilizada o incluso políticamente construible, idea que cae bajo la acusación de pertenecer a un pensamiento de la "totalidad", cuando no directamente "totalitario"» (Grüner, 1998: 37). De esta manera, paradójicamente, resulta ser el más fiel, cómplice y eficaz de todas las posiciones de un orden social totalizado invisibilizado, en tanto contribuye de forma descarada y sistemática a deconstruir todo sistema teórico que permita aproximarse a la comprensión del sistema social como totalidad articulada, ante lo cual no queda otra cosa que aceptar como única verdad y realidad posible al sistema-mundo capitalista, patriarcal y colonial (Grüner, 1998; Žižek, 1998; Kohan, 2013). De manera que, tal como defiende Grüner (1998: 40), «se pierde de vista - y se expulsa de la investigación teórica tanto como de la acción política- el lugar constitutivo (es decir, "estructural", es decir, cómo no, "totalizador") que sigue teniendo» el sistema de producción y acumulación capitalista.

No podemos seguir ignorando que la escuela es una institución del orden, no puede ser de otra manera. Como institución implicada en la socialización del sujeto - su producción-subjetivación-, se embarca en una tarea que tiene dos caras: incorporar al sujeto a un orden social existente e incorporar este orden social al sujeto. Asumir esto es reconocer la relación existente entre lo político, la política y la escuela y permite ubicar la discusión en toda su complejidad. No asumirlo no es solamente ofrecer otro relato, es pensar que la realidad es solo un texto, un discurso que encierra en sí mismo la verdad de un mundo de ficción que solo existe en su representación y que la violencia, la muerte, la dominación, la desigualdad y la injusticia solo son caprichos del autor. Hace tiempo que en la historia de la producción social del conocimiento se viene poniendo esto en cuestión (Marx y Engels, 1968; Borón y Cuellar, 1983; Volóshinov, 1992; Grüner, 1998; Lander, 2000), quizá aquí podamos encontrar alguna de las explicaciones de este proceso de deconstrucción.

No se trata de consenso ni armonía, sino de una tensa relación entre lo político, la política y la escuela, el conflicto y la tensión entre la ficción y lo real. Pero si en esta tensión no se busca un territorio para lo común y lo público como espacios reales desde los que pensar y cuestionar nuestro orden, las formas de compartir lo que producimos y un espacio para producir también un «compromiso para la creación de elementos colectivos, un compromi- 
so para fomentar los intereses comunes en cualquier aspecto de nuestras vidas» (Caffentzis y Federici, 2015: 70), entonces poco podemos hacer ante un sistema-mundo capitalista globalizado (Cole, Hill y Rikowski, 1997; McLaren y Farahmandpur, 2006). En este marco, una escuela que no esconda su tensa relación con lo político y la política es realmente necesaria.

\section{BIBLIOGRAFÍA}

Anderson, Benedict (2006). Comunidades imaginadas. Reflexiones sobre el origen y la difusión del nacionalismo. Madrid: Fondo de Cultura Económica.

Borón, Atilio (2002). Imperio \& Imperialismo. Una lectura crítica de Michael Hardt y Antonio Negri. Buenos Aires: CLACSO.

Borón, Atilio y Cuéllar, Oscar (1983). Apuntes críticos sobre la concepción idealista de hegemonía. Revista Mexicana de Sociología, $45(4), 1143^{-1177}$.

Bourdieu, Pierre (200o). Cuestiones de sociología. Madrid: Istmo.

Bourdieu, Pierre (2014). Intelectuales, política y poder. Buenos Aires: EUDEBA.

Caffentzis, George y Federici, Silvia (2015). Comunes contra y más allá del capitalismo. El Apantle, Revista de Estudios Comunitarios, 1, 5372 .

Cappelletti, Ángel (2010). La ideología anarquista. Barcelona: El grillo Libertario.

Castoriadis, Cornelius (1997). Democracy as procedure and democracy as regime. Constellations, 4(1), 1-18. https://doi.org/10.1111/1467-8675.00032

Castro-Gómez, Santiago (2000). Ciencias sociales, violencia epistémica y el problema de la «invención del otro». En Lander, Edgardo (Comp.). La colonialidad del saber: eurocentrismo y ciencias sociales. Perspectivas Latinoamericanas (88-98). Buenos Aires: CLACSO. 
Castro-Gómez, Santiago (2010). Historia de la Gubernamentalidad. Razón de Estado, liberalismo y neoliberalismo en Foucault. Bogotá: Siglo de Hombre.

Cole, Mike, Hill, Dave y Rikowski, Glenn (1997). Between Postmodernism and Nowhere: The Predicament of the Postmodernist. British Journal of Educational Studies, 45(2), 187-200. Cullen, Carlos (2008). Perfiles ético-políticos de la educación. Buenos Aires: Paidós.

Diker, Gabriel (2008). ¿Cómo se establece qué es lo común? En Frigerio, Graciela y Diker, Gabriela (Coords.). Educar: posiciones acerca de lo común (147-170). Paraná: Fundación la Hendija.

Durkheim, Émile (1996). Educación y sociología. Barcelona: Altaya.

Dussel, Enrique (2011). Filosofía de la liberación. México: Fondo de Cultura Económica.

Dussel, Inés (2007). La transmisión cultural asediada: Los avatares de la cultura común en la escuela. Propuesta Educativa, 28(2), 19-27.

Federici, Silvia (2014). Calibán y la bruja. Madrid: Traficantes de Sueños.

Fraser, Nancy y Jaeggi, Rahel (2019). Capitalismo. Una conversación desde la teoría crítica. Madrid: Morata.

Freire, Paulo (1985). Pedagogía del oprimido. Buenos Aires: Siglo Veintiuno.

Gandarilla, José G. (Coord.) (2016). La crítica en el margen: Hacia una cartografía conceptual para rediscutir la modernidad. México: Akal.

García Olivo, Pedro (2005). El enigma de la docilidad. Sobre la implicación de la Escuela en el exterminio global de la disensión y de la diferencia. Barcelona: Virus.

García Olivo, Pedro (2009). La bala y la escuela (Holocausto indígena). Modos en que la educación oficial complementa el trabajo represivo de las fuerzas policíacomilitares en los pueblos indios de México. Barcelona: Virus.

Gimeno Sacristán, José (200o). La educación obligatoria: su sentido educativo y social. Madrid: Morata. 
Grüner, Eduardo (1998). El retorno de la teoría crítica de la cultura: una introducción alegórica a Jameson y Žižek. En Jameson, Fredric y Zizek, Slavoj. Estudios Culturales. Reflexiones sobre el multiculturalismo (69-136). Buenos Aires: Paidós.

Grüner, Eduardo (2016). Teoría crítica y contra-Modernidad. En Gandarilla, José G. (Coord.). La crítica en el margen. Hacia una cartografía conceptual para rediscutir la modernidad (19-6o). México D.F.: Akal.

Kaplan, Carina y Ferrero, Federico (2003). La «Marca de Caín» o el regreso de las explicaciones deterministas a los discursos escolares bajo la impronta de la ideología neoliberal. Barbecho, Revista de Reflexión Socioeducativa, 3, 10-18.

Kohan, Nestor (2013). Nuestro Marx. Madrid: La Oveja Roja.

Lander, Edgardo (2000). Ciencias sociales: saberes coloniales y eurocéntrico. En Lander, Edgardo (Comp.). La colonialidad del saber: eurocentrismo y ciencias sociales. Perspectivas latinoamericanas (1-23). Buenos Aires: CLACSO.

Lundgren, Ulf P. (1992). Teoría del curriculum y la escolarización. Madrid: Morata.

Luxemburgo, Rosa (1975). La acumulación del capital. Barcelona: Orbis. Marx, Karl y Engels, Friedrich (1968). La ideología alemana. Montevideo: Pueblos Unidos.

McLaren, Peter y Farahmandpur, Ramin (2006). La Enseñanza contra el Capitalismo Global y el Nuevo Imperialismo. Una Pedagogía Crítica. Madrid: Popular.

Mies, Maria (2019). Patriarcado y acumulación a escala mundial. Madrid: Traficantes de sueños.

Monarca, Héctor (2011). La escuela fragmentada. Revista Iberoamericana de Educación, 57, 203-215.

Monarca, Héctor, Fernández-González, Noelia y Méndez-Núñez, Ángel (en prensa). Social order, regimes of truth and symbolic disputes: a framework to analyze educational policies. Filosofija. Sociologija, en prensa. 
Pineau, Pablo (2001). ¿Por qué triunfó la escuela?, o la modernidad dijo: "Esto es educación" y la escuela respondió: "Yo me ocupo". En Pineau, Pablo, Dussel, Inés y Caruso, Marcelo. La escuela como máquina de educar (27-52). Buenos Aires: Paidós.

Pineau, Pablo, Dussel, Inés y Caruso, Marcelo (2001). La escuela como máquina de educar. Buenos Aires: Paidós.

Popkewitz, Thomas (1994). Sociología política de las reformas educativas. Madrid: Morata.

Quijano, Aníbal (200o). Colonialidad del poder, eurocentrismo y América Latina. En Lander, Edgardo (Comp.). La colonialidad del saber: eurocentrismo y ciencias sociales. Perspectivas latinoamericanas (122-152). Buenos Aires: ClACSO.

Tomassi, Tina (1988). Breviario del pensamiento educativo libertario. Cali: Asociación Artística «La Cuchilla».

Trasatti, Filippo (2005). Actualidad de la pedagogía libertaria: con un breve diccionario introductorio. Madrid: Popular.

Volóshinov, Valentín N. (1992). El marxismo y filosofía del lenguaje. Madrid: Alianza.

Wallerstein, Immanuel (1983). Historical Capitalism with Capitalist Civilization. New York: Verso.

Yannuzzi, M. de los Ángeles (2009). El problema de la diferencia: Un balance desde la teoría política. KAIROS. Revista de Temas Sociales, $13(23), 1-13$.

Žižek, Slavoj (1998). Multiculturalismo o la lógica cultural del capitalismo multinacional. En Jameson, Fredric y Žižek, Slavoj. Estudios Culturales. Reflexiones sobre el multiculturalismo (137-187). Buenos Aires: Paidós.

Žižek, Slavoj (2007). En defensa de la intolerancia. Madrid: Sequitur.

Žižek, Slavoj (2016). El sublime objeto de la ideología. Buenos Aires: Siglo Veintiuno. 